\title{
A DINÂMICA DA COOPERAÇÃO: UM ESTUDO LONGITUDINAL EM REDES EMPRESARIAIS DO SETOR MOVELEIRO
}

\section{THE DYNAMICS OF COOPERATION: A LONGITUDINAL STUDY IN FURNITURE BUSINESS NETWORKS}

\author{
Douglas Wegner \\ Doutor em Administração pela Universidade \\ Federal do Rio Grande do Sul; Professor Adjunto \\ da Universidade de Santa Cruz do Sul \\ dwegner@unisc.br
}

\section{Greice De Rossi}

Mestre em Administração pela Universidade Federal do Rio Grande do Sul; Participante do Núcleo de Inovação RS - Sistema FIERGS greice_dr@yahoo.com.br

Tiago Franquini Scarano

Mestre em Engenharia de Produção pela Universidade Federal de Santa Maria; Técnico Extensionista do Projeto PEIEX/UNISC e Professor do Centro de Gestão Organizacional da UNIVATES

tiagoscarano@unisc.br
Contextus

ISSNe 2178-9258

Organização: Comitê Científico Interinstitucional Editor Científico: Marcelle Colares Oliveira Avaliação : Double Blind Review pelo SEER/OJS Revisão: Gramatical, normativa e de formatação Recebido em 23/03/2013 Aceito em 06/03/2014 $2^{\mathrm{a}}$. versão aceita em $24 / 03 / 2014$

\section{RESUMO}

Poucos estudos sobre redes interorganizacionais (RIOs) consideram o caráter dinâmico da cooperação e as mudanças que ocorrem ao longo do tempo. Partindo dessa lacuna, o estudo analisou as mudanças ocorridas entre 2004 e 2011 em duas RIOs constituídas por fábricas de móveis no Rio Grande do Sul. Para análise da trajetória das redes foram selecionadas três variáveis: gestão da cooperação e resultados obtidos pelos participantes; ambiente relacional da rede e confiança entre os participantes; e, apoio de agentes externos. Verificou-se que, apesar dos resultados positivos que essas redes obtinham em 2004 e do desenvolvimento de um ambiente relacional favorável entre os empresários, a complexidade gerencial e a ocorrência de eventos críticos levaram uma delas ao encerramento e a outra a reduzir as atividades cooperativas. Gerar novos benefícios à medida que mudam os interesses individuais e ocorrem eventos críticos é um desafio para a gestão de RIOs.

Palavras-chave: Redes interorganizacionais. Redes de pequenas empresas. Cooperação. Dinâmica.

\begin{abstract}
Few studies on interorganizational networks (ION) consider the dynamic nature of cooperation and occurring changes over time. Based on this gap, we analyzed the changes between the years of 2004 and 2011 in two furniture business networks in the state of Rio Grande do Sul. To the network trajectory analysis, three variables were selected: cooperation management and results obtained by participants; relational environment and trust among participants and, external agents support. It was verified that managerial complexity and the critical events which occurred led to the closure of one network, despite the positive results networks achieved in 2004 and the development of a favorable relational environment among members. The other network had its cooperative activities reduced. A big challenge for the management of ION is to provide new benefits to the firms as entrepreneurs' individuals interests change.
\end{abstract}

Keywords: Interorganizational networks. Small-firm networks. Cooperation. Dynamics. 


\section{INTRODUÇÃO}

Desde que as relações interorganizacionais (RIOs) passaram a ser objeto de análise da academia, poucos estudos se preocuparam em compreender as mudanças e a dinâmica dos arranjos cooperativos. Como destacam Doz (1996), Sydow (2003), Oelsnitz e Tiberius (2007) e Tiberius (2008), a maioria dos estudos trata as RIOs como estruturas estáticas, desconsiderando sua natureza dinâmica. Para exceções, pode-se consultar os estudos de Ring e Van de Ven (1994), Spekman et al. (1998), Ahlström-Söderling (2003), Sydow (2004) e Jiang, Li e Gao (2008), segundo os quais as redes possuem uma dinâmica própria de desenvolvimento e não permanecem estáticas. Conforme Cropper e Palmer (2008), as poucas pesquisas que analisaram a dinâmica da cooperação concentraram-se principalmente em registrar e explicar mudanças em termos de composição, constituição, escopo e intensidade de atividades e de interações entre as organizações. Sydow (2003) reforça que uma das lacunas no que se refere à dinâmica da cooperação é a falta de estudos que analisam se as mudanças e o desenvolvimento das redes podem ser diretamente influenciados pelos participantes ou se eles ocorrem devido a eventos emergentes e com consequências inesperadas.
Analisar a dinâmica da cooperação é importante porque permite compreender que mudanças ocorrem em redes interorganizacionais com o passar do tempo e que mecanismos provocam ou influenciam essas mudanças (AHUJA, SODA e ZAHEER, 2012). Pesquisas sobre esse tema podem servir como indicativos para identificar fatores que contribuem para o sucesso ou $\mathrm{o}$ fracasso da cooperação. Do ponto de vista gerencial, os resultados de pesquisas longitudinais podem oferecer informações aos gestores de redes interorganizacionais sobre aspectos que devem ser considerados para garantir a continuidade da cooperação e, até mesmo, sobre mudanças que devem ser deliberadamente conduzidas para manter o sucesso do arranjo cooperativo. Com base nesse contexto, o presente estudo tem como propósito central analisar a dinâmica da cooperação e as mudanças ocorridas em duas redes horizontais de empresas do setor moveleiro, no período de 2004 e 2011.

$\mathrm{O}$ artigo está estruturado em cinco seções. Além desta introdução, a seção 2 apresenta uma revisão das teorias que analisam a dinâmica de desenvolvimento de redes interorganizacionais e propõem a existência de fases ou estágios da cooperação, destacando três elementos teóricos que são analisados na pesquisa empírica. A seção 3 descreve a metodologia de pesquisa, detalhando o 
protocolo de pesquisa, as técnicas de coleta e a análise de dados utilizados. A seção 4 expõe os resultados da pesquisa, comparando as redes interorganizacionais em dois momentos, separados por um período de tempo de sete anos. Nessa mesma seção também se discutem os resultados à luz da base teórica utilizada, de acordo com os objetivos do estudo. A quinta e última seção resgata as principais conclusões do estudo e apresenta suas limitações, bem como aponta sugestões de estudos futuros.

\section{REDES INTERORGANIZACIONAIS: DINÂMICA DE DESENVOLVIMENTO}

Redes interorganizacionais estão sujeitas à evolução dinâmica porque as estruturas, os resultados e as avaliações dos atores envolvidos mudam ao longo do tempo, e as próprias mudanças nos resultados obtidos com a cooperação são capazes de gerar processos dinâmicos de desenvolvimento (EBERS e GRANDORI, 1999). Processos de reavaliação, aprendizagem e adaptação podem levar a ajustes internos da relação cooperativa e, inclusive, à possibilidade de encerramento dos acordos originalmente estabelecidos. Florén e Tell (2004) argumentam que a interação continuada de atores em rede pode levar ao esgotamento das diferenças que constituíam uma vantagem para os participantes.
A evolução de um arranjo cooperativo pode ser comparada à noção de ciclo de vida, movendo-se de um estágio de contatos iniciais, através de negociações e lançamento da ideia, para uma fase de cooperação gerenciada (CHILD, 2001). Em geral, a constituição de redes de empresas passa por uma etapa de contatos iniciais e seleção dos potenciais integrantes do arranjo (ZINELDIN, 2002; JIANG, LI e GAO, 2008); a essa etapa segue-se a formatação e o estabelecimento de mecanismos legais e regulamentos que mediarão contratualmente a relação cooperativa (AHLSTRÖM-SÖDERLING， 2003). O desenvolvimento da rede caracteriza-se pela elaboração de um planejamento estratégico, como guia de ações e fortalecimento da cooperação. Nessa etapa, surge a necessidade de criação de mecanismos de governança (ALBERS, 2010) e o estabelecimento de práticas de gestão sem as quais dificilmente os objetivos serão alcançados.

Sydow (2004), em oposição a Child (2001), Zineldin, (2002), AhlströmSöderling (2003) e Jiang, Li e Gao (2008), acredita que as fases de desenvolvimento das redes interorganizacionais não devem ser tomadas como um modelo, já que elas possuem dinâmica fluida e as mudanças não podem simplesmente ser divididas em etapas. Para Sydow (2004), não existe uma 
sequência linear justamente porque ocorrem eventos que afetam significativamente a evolução de uma rede, tornando-a não-linear. Como exemplos de eventos críticos, o autor cita a ocorrência de quebras de confiança, a entrada de novas organizações na rede ou a saída de membros. Esses eventos geram mudanças na estrutura da rede, nos seus resultados e mesmo no ambiente relacional do grupo. Assim, situações que frequentemente ocorrem em redes interorganizacionais podem alterar sua evolução linear. Em outro estudo, Sydow (2003) argumenta que a continuidade de uma rede pode estar condicionada à sua capacidade de reiniciar o ciclo de desenvolvimento e retomar atividades de estágios anteriores, já que é provável que ocorram eventos impactantes ao longo do tempo que não permitem à rede evoluir de maneira linear.

\subsection{Elementos de análise da dinâmica da cooperação}

Diversos elementos podem influenciar a dinâmica de desenvolvimento de uma rede, tanto no nível das empresas individuais como em termos dos relacionamentos entre os participantes. Neste estudo foram selecionados e analisados três elementos específicos: a gestão da cooperação e os resultados obtidos pelos participantes; o ambiente relacional dentro da rede; o papel dos agentes externos no apoio à cooperação. A confiança é destacada por diversos autores como um dos elementos centrais da cooperação $\quad$ (SYDOW, 1998; BACHMANN，2001; BALESTRIN e VARGAS，2004; KRISHNAN，2006) e, portanto, pressupõe-se que tenha papel relevante também para o desenvolvimento da cooperação ao longo do tempo. Da mesma forma, a necessidade de uma gestão eficiente para a obtenção de resultados através da cooperação é considerada condição sine qua non para manter o interesse dos participantes ao longo do tempo (PARK e UNGSON, 2001; VERSCHOORE, 2004; HIBBERT et al., 2008). Finalmente, o terceiro elemento de análise foi escolhido devido ao apoio externo de órgãos e programas públicos, recebido por diversas redes durante o processo de constituição e que teve importância significativa para o surgimento de um grande número de RIOs no estado do Rio Grande do Sul (VERSCHOORE, 2004). Esses três elementos são apresentados sinteticamente nas próximas subseções do artigo.

\subsubsection{Gestão da cooperação e resultados para os participantes}

Para que uma rede se mantenha ativa com o passar do tempo é indispensável que os ganhos provenientes da cooperação sejam superiores, no longo prazo, aos lucros que podem ser obtidos fora da rede, e que os mecanismos de 
divisão dos resultados entre os participantes sejam justos (JARILLO, 1988). Se essas duas condições forem satisfeitas, a rede poderá se manter ao longo do tempo. Do contrário, os participantes que consideram os resultados da rede insatisfatórios ou a divisão dos benefícios injusta tendem a desistir da cooperação, podendo levar ao encerramento da rede. Amaldoss et al. (2000) complementam que, quando os parceiros dividem os benefícios igualmente, o comprometimento aumenta mais rapidamente. Porém, quando os parceiros percebem que outros usufruem de maiores benefícios, é natural que se sintam menos compelidos a cooperar e que seu comprometimento seja afetado.

A gestão da rede assume papel fundamental para facilitar o alcance de resultados efetivos e para garantir que esses resultados beneficiem simetricamente os participantes. No entanto, a gestão da cooperação demanda grandes esforços de coordenação devido à complexidade gerencial e à incerteza que caracteriza empreendimentos desse tipo (PARK e UNGSON, 2001). Em redes formadas por um grande número de empresas, é natural que haja desajustes entre os participantes, tornando-se fundamental uma sólida relação de confiança entre as partes envolvidas (MELLAT-PARAST e DIGMAN, 2008), aspecto que será abordado na próxima seção.
Além disso, a gestão das redes de empresas traz consigo dificuldades relacionadas principalmente à heterogeneidade dos envolvidos. "A organização formada para sustentar a formação e o crescimento das redes deve ser capaz de lidar com um conjunto amplo de expectativas, objetivos e estilos de administração dos associados" (VERSCHOORE, 2004, p. 37). Cada empresa carrega uma cultura própria e práticas de gestão diferentes das dos demais parceiros. É no processo de cooperação que essas diferenças se tornam latentes e precisam ser ajustadas ou aceitas, para que a rede tenha sucesso. Mesmo não sendo uma tarefa fácil, quando há uma sinergia nesse processo, a rede potencializa as competências individuais e aumenta as oportunidades coletivas (OLIVEIRA, REZENDE, CARVALHO, 2011). Segundo Hibbert et al. (2008), a gestão de uma rede interorganizacional refere-se a uma série de processos e práticas realizadas por um time de indivíduos, focadas tanto na definição da direção a ser tomada por uma entidade interorganizacional quanto na alocação e implementação de recursos para alcançar esses fins. A principal diferença entre gestão hierárquica e gestão de redes é que a última incorpora constante negociação e renegociação entre um grupo de atores autônomos, enquanto a primeira é baseada na autoridade (JÄRVENSIVU e 
MÖLLER, 2009). A gestão de uma rede interorganizacional implica mudanças significativas nas práticas e nos papéis dos gestores, em comparação com aquelas utilizadas em organizações hierárquicas e corporações (SYDOW, 2006), demandando habilidades especiais dos líderes (PROVAN e LEMAIRE, 2012).

Para Järvensivu e Möller (2009), a gestão de redes precisa assegurar que quatro requisitos-chave sejam desenvolvidos. Primeiramente, é fundamental que haja uma agenda de criação de valor e um plano sobre como a cooperação pode gerar esse valor. Depois, atores, recursos e atividades precisam ser identificados e coordenados. O terceiro requisito é que os atores precisam ser mobilizados para realizar as atividades necessárias, pois cooperam voluntariamente. Finalmente, se as atividades de criação de valor não produzem os resultados planejados, a gestão da rede precisa realizar medidas corretivas para aperfeiçoar a cooperação.

Depreende-se, portanto, que uma gestão eficiente é fundamental para que a rede possa se desenvolver. Conforme Wegner e Padula (2010) e Wegner et al. (2013), a profissionalização da gestão torna-se mais importante à medida que a rede se desenvolve, uma vez que se torna praticamente inviável aos empresários gerenciar a rede em paralelo ao próprio negócio, com a dedicação de tempo necessária para as atividades cooperativas.

\subsubsection{Confiança}

Não é possível falar em dinâmica interorganizacional e desenvolvimento de uma rede de empresas sem fazer referência à importância da confiança entre as partes e de um ambiente relacional favorável. A relação entre confiança e cooperação vem sendo trabalhada extensivamente pelo meio acadêmico (por exemplo, pelos autores Sydow, 1998; Andrade et al., 2011; Huang e Wilkinson, 2013), demonstrando que o sucesso de uma RIO está fortemente baseado na existência de confiança entre os atores.

O nível de confiança dos empresários nos seus parceiros nos estágios iniciais da cooperação deixa fortes marcas no desenvolvimento dos relacionamentos em estágios posteriores (VLAAR, VAN DEN BOSCH e VOLBERDA, 2007). Quando não há confiança e o risco de oportunismo percebido pelos participantes é alto, o custo de gerenciamento da cooperação, por meio de contratos e salvaguardas, pode torná-la inviável. Outra consequência da falta de confiança é que ela pode levar à restrição em compartilhar informações e conhecimentos, aspecto de grande importância para a manutenção do interesse em cooperar. 
Pode-se definir a confiança interorganizacional como a expectativa de uma empresa de que outra não irá explorar suas vulnerabilidades quando confrontada com a possibilidade de fazê-lo (KRISHNAN, 2006). Essa expectativa é confirmada quando as partes cumprem suas promessas, agem de maneira justa nas interações uns com os outros e utilizam da benevolência quando surgem situações imprevistas.

De acordo com Franco (2007), a identificação de oportunidades de colaboração, a definição de objetivos claros e uma significativa atenção na seleção das organizações participantes são apectos a considerar para a redução de potenciais dificuldades e para a criação de um ciclo de confiança já no início da cooperação. Sydow (1998) complementa que as propriedades estruturais da rede podem ser importantes para favorecer a construção da confiança no ambiente cooperativo, como por exemplo: a frequência, a abertura e a densidade da comunicação interorganizacional; a multiplicidade das relações na rede (os tipos diferentes de informações e relações entre distintos participantes); a nãofinitude das relações, denominada sombra do futuro por Axelrod (1984); uma relação equilibrada entre autonomia e dependência (nos dois extremos a confiança não é necessária); o número e a homogeneidade das organizações na rede; a estrutura do campo interorganizacional.

Com base nos estudos teóricos de Bachmann (2001), Sydow (1998) e Krishnan (2006), argumenta-se que a confiança e, de uma forma mais ampla, o ambiente relacional da rede (envolvendo comprometimento, resolução de conflitos, confiança), atuam como elemento mediador na dinâmica de uma rede interorganizacional. Esse elemento tem papel fundamental como influenciador para os avanços e retrocessos da rede nas diversas etapas, desde sua formação, passando pelo desenvolvimento e pela consolidação. Contudo, isso não significa que, uma vez consolidada, a rede prescinda desse elemento. No estudo de Esteves e Nohara (2011), a falta de confiança entre os atores foi um dos principais motivos para a instabilidade de uma rede brasileira caracterizada como consórcio de exportação. Andrade et al. (2011), por sua vez, verificaram empiricamente que a confiança reduz os custos de negociação e de monitoramento em RIOs.

No entanto, a confiança nos relacionamentos interorganizacionais não é estática. Segundo Khanna, Gulati e Nohria (1998), uma importante razão para o desapontamento de muitas firmas com alianças estratégicas se deve à falta de compreensão sobre a dinâmica da confiança dos relacionamentos. Schilke e 
Cook (2013) enfatizam o caráter dinâmico da confiança ao longo dos estágios de desenvolvimento das relações interorganizacionais. É possível que surjam assimetrias de incentivos para investir na relação, à medida que a cooperação evolui.

A dinâmica das redes interorganizacionais, em si, reúne uma série de aspectos que permeiam a cooperação e a competição (CASTRO, BULGACOV e HOFFMANN, 2011), que refletem nos interesses e objetivos estabelecidos e, por consequência, na confiança entre as empresas envolvidas. Monitorar as expectativas e observar quanto elas continuam alinhadas, à medida que a rede avança, é importante para manter o interesse de colaboração de todas as partes e um ambiente relacional positivo.

\subsubsection{Apoio de órgãos externos}

$\mathrm{O}$ apoio de órgãos públicos $\mathrm{e}$ instituições também é um aspecto considerado importante para o sucesso na formação e no desenvolvimento de RIOs. Ao relatarem a experiência italiana, Casarotto e Pires (1998) apontam a existência de atores locais como fator necessário para o sucesso de empreendimentos colaborativos. A cooperação entre empresas acontece com maior facilidade quando, no seu entorno, há toda uma estrutura de sustentação e apoio. A relevância do suporte institucional para o sucesso das redes de empresas também é citada por Humphrey e Schmitz (1995) no caso da Dinamarca, em que a existência de um programa governamental para a formação de redes foi importante para estimular as companhias locais a superarem a resistência à cooperação, que não fazia parte da cultura industrial do país. O apoio institucional permite que se atinja maior escala de participantes em menos tempo e, no caso da Dinamarca, ajudou a transformar as redes em uma opção estratégica competitiva para as empresas.

No estado do Rio Grande do Sul, o poder público assumiu o papel de coordenação e desenvolvimento do ambiente institucional para a criação e o desenvolvimento de redes de empresas de pequeno porte. Segundo Verschoore (2004), através do Programa Redes de Cooperação, o estado atuou como um facilitador na difícil tarefa de modificar uma cultura de competição e inserir o paradigma da colaboração empresarial, além de articular um conjunto de atores institucionais que apoiaram as redes em seu processo de formação e desenvolvimento, como, por exemplo, as universidades regionais e os consultores das redes. Atualmente, segundo dados da Secretaria da Economia Solidária e Apoio à Micro e Pequena Empresa - Sesampe 
(2013), estão em funcionamento no Rio Grande do Sul 237 redes constituídas que abrangem 72 segmentos da economia.

Hastenreiter Filho

argumenta que agentes externos ou intermediadores contribuem positivamente no sentido de mobilizar as empresas e convencê-las da importância de ações associativas. Tais agentes iniciam o processo associativo com uma configuração inicial definida e agem como minimizadores de conflitos, aumentando as chances de sucesso do empreendimento coletivo. Wegner, Zen e Andino (2011) relatam que a dependência das redes em relação ao apoio do agente externo pode gerar significativas dificuldades quando ocorrem interrupções ou paradas nos programas de apoio. Entre as consequências identificadas pelos autores estão o surgimento de divisões internas entre os participantes e a saída de empresas da rede, enfraquecendo a cooperação. Em estudo realizado num arranjo produtivo local do setor calçadista, Cunha, Passador e Passador (2012) verificaram que o agente externo tem papel importante para unir os interesses de curto prazo dos membros da rede, cooperação que possivelmente não ocorreria sem o seu apoio. No entanto, esse agente não tem o poder de alavancar relações sociais fortes, caso não existam fortes laços munidos de capital social entre as empresas participantes. Isto é, as relações estabelecidas são focadas em aspectos comerciais e econômicos, mas não sociais e relacionais, fazendo com que as ações do agente externo ou intermediador estejam sustentadas somente por uma racionalidade de mercado, e não por uma lógica social que poderia sustentar a rede com o passar do tempo Os agentes intermediadores são importantes, mas não fundamentais para a rede: "o agente é um estimulante, mas não o elemento central da rede. O elemento central são as relações em si e o output que a rede pode produzir" (CUNHA, PASSADOR e PASSADOR, 2012, p. 122).

A Figura 1 apresenta sinteticamente os três elementos de análise e os autores de referência, servindo de base para a elaboração do estudo empírico. 
Figura 1 - Elementos de análise e autores de referência

\begin{tabular}{|c|c|c|}
\hline Elemento de análise & Aspectos-chave & Autores de referência \\
\hline $\begin{array}{l}\text { Gestão da cooperação e } \\
\text { resultados }\end{array}$ & $\begin{array}{l}\text { - resultados efetivos e divisão justa são } \\
\text { indispensáveis para manter o interesse na } \\
\text { cooperação; } \\
\text { - a criação de uma estrutura de gestão para a } \\
\text { rede é relevante para seu desenvolvimento, } \\
\text { especialmente quando aumenta o número de } \\
\text { participantes; }\end{array}$ & $\begin{array}{c}\text { Wegner e Padula (2010); } \\
\text { Verschoore (2004); } \\
\text { Hibbert et al. (2008); Järvensivu } \\
\text { e Möller (2009) } \\
\text { Provan e Lemaire (2012) } \\
\text { Wegner et al. (2013). }\end{array}$ \\
\hline Confiança & $\begin{array}{l}\text { - a confiança e um ambiente relacional positivo } \\
\text { têm importância para o sucesso da cooperação; } \\
\text { - os relacionamentos interpessoais influenciam a } \\
\text { dinâmica de desenvolvimento de RIOs. }\end{array}$ & $\begin{array}{l}\text { Bachmann (2001); } \\
\text { Sydow (1998); } \\
\text { Krishnan (2006); Schilke } \\
\text { e Cook (2013) Vlaar, Van } \\
\text { Den Bosch e Volberda (2007) } \\
\text { Huang e Wilkinson (2013) } \\
\text { Franco (2007) }\end{array}$ \\
\hline Agentes externos & $\begin{array}{l}\text { - os agentes externos possuem importante papel } \\
\text { na constituição e no desenvolvimento da rede; } \\
\text { - os agentes atuam como fomentadores das ações } \\
\text { iniciais e da organização da cooperação. }\end{array}$ & $\begin{array}{c}\text { Casarotto e Pires (1998); } \\
\text { Humphrey e Schmitz (1995); } \\
\text { Verschoore (2004); } \\
\text { Hastenreiter Filho (2005); } \\
\text { Wegner, Zen e Andino (2011); } \\
\text { Cunha, Passador e Passador } \\
\text { (2012) }\end{array}$ \\
\hline
\end{tabular}

Fonte: elaborada pelos autores.

\section{METODOLOGIA DE PESQUISA}

Com base na proposta de pesquisa para o presente estudo, optou-se pela realização de dois estudos de caso, com abordagem qualitativa e caráter longitudinal. A abordagem qualitativa foi escolhida porque permite ao pesquisador "[...] estudar as coisas em seus cenários naturais, tentando entender, ou interpretar, os fenômenos em termos dos significados que as pessoas a elas conferem" (DENZIN e LINCOLN, 2006, p. 17). Isto é, a pesquisa qualitativa "[...] está interessada na perspectiva dos participantes, em suas práticas do dia-a-dia e em seu conhecimento cotidiano relativo à questão em estudo" (FLICK, 2009, p. 16), permitindo, nesse caso, compreender como os participantes de redes interorganizacionais perceberam a dinâmica do processo de cooperação. O retorno ao campo para verificar as mudanças que ocorreram no objeto de estudo, analisar evoluções e mudanças, caracteriza esta pesquisa como longitudinal (FLICK, 2009).

Como objeto de estudo, foram selecionadas duas redes horizontais formadas por empresas do setor moveleiro, alvo de estudo no ano de 2004. A opção por esses dois casos deve-se ao fato de serem redes consideradas bem-sucedidas pelos empresários participantes na coleta de dados em 2004. A primeira rede analisada é a Associação dos Fabricantes de Estofados e Móveis Complementares 
(Rede Afecom), localizada no polo moveleiro da serra gaúcha, com sede no município de Bento Gonçalves (RS). A segunda rede é o Núcleo Moveleiro de Santa Maria (Rede Numov-SM), com sede na cidade de Santa Maria (RS). As duas redes caracterizam-se como redes burocráticas simétricas, segundo a tipologia de Grandori e Soda (1995), já que são formalizadas e todos os associados têm o mesmo poder de participar das decisões e das definições estratégias do grupo. Podem também ser consideradas redes flexíveis de pequenas empresas, conforme classificação proposta por Casarotto e Pires (1998).

\subsection{Protocolo de pesquisa e técnicas de coleta e análise de dados}

O roteiro de pesquisa foi construído a partir das variáveis apresentadas na revisão teórica e conforme Quadro 1, incluindo as variáveis: gestão da cooperação e resultados obtidos pelos participantes; confiança entre os participantes; apoio externo para estabelecimento e desenvolvimento da rede. Além disso, coletaram-se dados gerais sobre as redes, como seu processo de criação, nível de estruturação em 2004 e em 2011 e número de participantes. A coleta de dados ocorreu em dois momentos, com um intervalo de sete anos. Tanto em 2004 quanto em 2011 foram realizadas entrevistas em profundidade com representantes das redes.
No caso da Rede Afecom, as entrevistas foram realizadas em 2004 e 2011 com o vice-presidente da rede, na sede da sua empresa, na cidade de Farroupilha (RS). Já no caso da Rede Numov-SM as entrevistas foram realizadas com dois empresários, na sede das suas empresas em Santa Maria (RS): o empresário A foi entrevistado em 2004, quando era presidente da rede, e voltou a ser entrevistado em 2011; o empresário B foi entrevistado em 2011, por ser o atual presidente da rede. Os entrevistados foram selecionados devido ao papel que desempenharam na criação e no desenvolvimento das redes, sendo considerados informantes-chave para descrever a dinâmica da cooperação e os desdobramentos das respectivas redes no período analisado.

As entrevistas tiveram duração entre 30 e 60 minutos, tendo sido gravadas e transcritas. Para facilitar o entendimento do leitor, o resultado da pesquisa é apresentado em subseções que descrevem as redes em cada período analisado.

\section{A DINÂMICA DA COOPERAÇÃO EM REDES INTERORGANIZACIONAIS}

Embora as relações interorganizacionais possam ser estabelecidas com objetivos específicos e prazo de tempo predeterminado, as redes formadas por pequenas empresas de um mesmo segmento são, via de regra, 
constituídas para gerar resultados duradouros e manter as atividades cooperativas. No entanto, esse fato não impede que ocorram mudanças significativas e mesmo a dissolução da rede, se os participantes não estiverem satisfeitos. As subseções seguintes apresentam os resultados da pesquisa com as duas redes anteriormente citadas.

\subsection{A Rede Afecom em 2004: de vento em popa}

A Afecom era uma rede de fabricantes de estofados e móveis composta por 21 fábricas localizadas na serra gaúcha. Foi criada em 2001 com o objetivo de gerar escala para aquisição de matérias-primas e exportar conjuntamente, buscando também melhorar o design dos produtos das empresas participantes, criar novos produtos, obter qualificação, competitividade e uma maior integração dos fabricantes com os fornecedores e lojistas da cadeia produtiva. Segundo Balestro e Mesquita (2002), a localização das empresas em um Sistema Local de Produção facilitou a articulação de uma série de atores para a constituição da rede, como a Associação das Indústrias de Móveis do Estado do Rio Grande do Sul (MOVERGS), o Centro Tecnológico do Mobiliário (Cetemo/Senai), o Sindicato da Indústria Moveleira (Sindimóveis) e, à epoca, a Secretaria do Desenvolvimento e dos Assuntos Internacionais (Sedai) do governo do estado, através de parceria com a Universidade de Caxias do Sul.

As empresas participantes tinham uma ampla variedade de produtos, desde modelos simples até peças sofisticadas. De acordo com o empresário entrevistado, a ideia de cooperação empresarial teve início com os problemas enfrentados por um conjunto de empresas em relação ao fornecimento de espuma e componentes para estofados, cuja solução foi importar esses insumos em conjunto. À medida que o grupo se organizava, percebeu-se que eram necessários mais parceiros e que produzir somente estofados não seria suficiente para que a rede pudesse conquistar mercado, de maneira que novas empresas produtoras de móveis passaram a fazer parte do grupo. Em 2004, a rede estava organizada com uma diretoria que apresentava presidente e vice-presidente, além de comissões como marketing, tecnologia e qualidade, que contavam com a participação de $90 \%$ dos empresários da rede.

A rede estruturou um Centro de Distribuição em Miami, nos Estados Unidos, e não estava preocupada apenas em buscar novos mercados para os seus associados, mas também em melhorar a qualidade, o design e a organização das empresas individualmente. A rede procurava aperfeiçoar a gestão das empresas participantes, a gestão da qualidade e buscava, em 2004, a 
certificação ISO 9000 e a gestão de tecnologias limpas, visando a sustentabilidade ambiental das empresas. Segundo o empresário, o objetivo da rede para ampliar as atividades cooperativas era despersonalizar as empresas e tornar a Afecom uma organização de venda, criando produtos com a marca da rede, feitos pelas empresas que a compõe. Havendo pedidos, a empresa que fabrica o móvel receberia a encomenda e, eventualmente, repassaria pedidos para suas parcerias em função da quantidade a ser produzida.

O entrevistado, ao comentar sobre o relacionamento das empresas na rede, afirmou que, em 2004, o nível de relacionamento entre os participantes era muito maior do que em 2001, ano de sua formação. Para o empresário, "é inevitável que surjam conflitos, já que todos os empresários são líderes na sua empresa, dentre os quais precisa surgir um novo líder na rede, [...] alguém que entenda as diferenças individuais, os posicionamentos das pessoas, que entenda de psicologia e de interação social". Por esses motivos, a rede definiu que as empresas que pretendessem ingressar seriam pesquisadas e preparadas, isto é, passariam por visitas e levantamento de informações sobre qualidade, tempo de produção, identificação do empresário com o cooperativismo e sobre a sua motivação em fazer parte da rede.
Além da questão cultural e da noção de associativismo, o dirigente ressaltou que é fundamental que haja objetivos claros e bem definidos, como ponto de partida da rede. Com o passar do tempo, tanto as empresas quanto as pessoas passam a se conhecer melhor e aumentam a sua interação, a partir da qual ocorre um processo de seleção natural dentro da rede, com saída de parceiros antigos e entrada de novos. O empresário afirmou também ser importante a existência de um agente catalisador das atividades.

O processo de consolidação da rede ocorre
com maior facilidade a partir da
participação de associações comerciais,
industriais, sindicatos e da própria
universidade, já que essas instituições têm
estruturas estabelecidas e podem ajudar o
grupo em momentos de maior fragilidade
ou quando ocorrem divergências.

Em relação aos principais ganhos da rede, o dirigente afirmou na época que foram os seguintes: o crescimento da qualidade dos produtos, o faturamento e, em termos de relacionamento, a superação da visão míope de que "eu tenho que me fechar dentro da minha empresa porque ninguém pode ver o que eu estou fazendo". Quando questionado sobre a chave para o sucesso de qualquer rede que esteja surgindo ou em processo de formação, o entrevistado afirmou que é preciso ter objetivos claros e focados, com indicadores para avaliar todos os passos, acompanhar tudo o que se está fazendo. A rede Afecom possuía uma estrutura de 
gestão com profissionais contratados exclusivamente para a rede, responsáveis por prospectar mercados, promover as vendas e fazer a gestão da rede. No ano de 2004, a rede já apresentava metas de exportação estabelecidas até 2010. Nas palavras do empresário,

[...] a rede é a construção de uma história que é feita aos poucos, necessitando de um amadurecimento, e não é algo que acontece em um ano. Ela tem todo um amadurecimento até que as pessoas consigam olhar umas no fundo dos olhos das outras. Tem que adquirir confiança entre as pessoas e isto é um pouco complicado porque é um processo cultural.

\section{2 "Dinheiro grande tem que andar} com dinheiro grande": o encerramento da rede Afecom

A rede Afecom encerrou suas atividades em 2008, contando na época com somente três associados. Um dos principais motivos citados pelo empresário entrevistado para o fracasso na continuidade da cooperação foi a ideia de realizar vendas conjuntas, destacada na entrevista de 2004. "Comprar em conjunto em redes é bom, mas vender em rede é um pouco mais complicado [...]. Nós tínhamos dentro da rede empresas que atendiam classe A, outras B, outras C e outras bem populares mesmo, então os interesses e objetivos eram diferentes". Segundo o entrevistado, "nós geramos uma grande confusão na cabeça dos nossos clientes, e isso não ficou legal". A diferença de porte das empresas, com capacidades de produção muito distintas, também acabou dificultando o alinhamento das empresas na rede.

Ao longo da entrevista, também esteve latente que algumas empresas saíram da rede quando perceberam que haviam atingido objetivos individuais: "foi algo como 'não tenho mais interesse porque eu abri o meu mercado e eu não preciso mais de vocês' [...]. Isso é coisa de pessoas que não têm cabeça de cooperação, não sabem trabalhar em uma associação". Quando mudanças no câmbio prejudicaram as exportações, as empresas perderam competitividade no mercado internacional - um dos objetivos estratégicos da rede - e decidiram por fechar o centro de distribuição nos Estados Unidos. Em contrapartida, resolveu-se investir na abertura de uma loja da rede em Porto Alegre (RS); contudo, a abertura da loja revelou-se uma estratégia equivocada, gerando custos elevados sem o retorno esperado. Segundo o empresário, a rede deveria ter focado exclusivamente em aspectos referentes à compra conjunta de insumos. Entretanto, mesmo essa ação ficaria prejudicada porque havia empresas com problemas de cadastro, inviabilizando a conciliação das compras e a posterior distribuição entre os associados.

Embora tenham surgido diferenças em termos de objetivos e comprometimento dos participantes com o passar do tempo, o empresário destaca que 
não houve grandes problemas de relacionamento dentro da rede a ponto de inviabilizar a cooperação. Um dos resultados mais importantes gerados pela rede foi justamente a troca de informações e conhecimentos, que continua ocorrendo entre algumas empresas mesmo após o término das atividades da rede. No entanto, as diferenças de porte das organizações geraram problemas determinantes para o desenvolvimento da Afecom: "a gente dizia na época que dinheiro pequeno deve andar com dinheiro pequeno, dinheiro grande tem que andar com dinheiro grande, não tem como andar juntos", referindo-se à incapacidade de algumas empresas de fazer os investimentos definidos pelo grupo. As estratégias e as possibilidades de empresas com tamanhos diferentes acabaram por não se alinhar e levaram ao desligamento de diversas empresas da rede.

Quanto ao apoio externo recebido pela rede das entidades representativas e do governo do estado, à época da formação, o empresário acredita que "foi um trabalho de muito curto prazo, foi um trabalho de informação, não de formação [...]. As pessoas [que apoiaram a rede no processo de constituição] eram muito entusiastas e pouco realistas". Assim, entende que não houve um planejamento integrado e acessível a todos, considerando as diferentes realidades de formação e experiência dos empresários. Alguns representantes de empresas menores “estavam buscando na associação um novo patrão, que resolvesse todos os seus problemas", e isso não ocorreu porque não é característico do modelo de cooperação em rede.

\subsection{Rede Numov-SM em 2004: ainda aprendendo a cooperar}

A rede Numov-SM surgiu devido a um problema enfrentado pela indústria moveleira na região da cidade de Santa Maria (RS): a falta de mão de obra especializada na área de fabricação de móveis. Essa necessidade estimulou a união de um grupo de empresas para pleitear um curso de marcenaria junto ao Serviço Nacional da Indústria (Senai), com o incentivo da Câmara de Comércio e Indústria de Santa Maria (Cacism) e o Serviço Brasileiro de Apoio às Micro e Pequenas Empresas (Sebrae), grupo esse que posteriormente originou a Numov-SM. A partir da primeira experiência positiva do grupo, houve a percepção de que seria possível obter outros benefícios através do trabalho conjunto, surgindo a ideia de formar uma rede de cooperação, constituída em fevereiro de 2003 por 20 pequenas empresas moveleiras.

Em 2004, a rede organizava-se por meio de uma diretoria com presidência e vice-presidências, com objetivos específicos para os quais os participantes direcionavam seus esforços. Essa estrutura garantiu que todos os empresários 
estivessem de alguma forma envolvidos com a busca de resultados para a coletividade. A Numov também realizou seminários de planejamento estratégico, visando determinar objetivos e formas de alcançá-los. As empresas participantes da rede atuavam com as seguintes linhas de produtos sob medida: dormitórios, cozinhas e móveis para laboratórios e lojas.

Segundo estimativas do grupo, as empresas participantes detinham cerca de $22 \%$ da demanda de móveis sob medida da cidade de Santa Maria.

Em relação ao início das atividades da rede, o empresário A (presidente da rede na época) afirmou que os participantes não compartilhavam todas as suas informações, prevalecendo a noção de que "eu faço as coisas da maneira certa", cujos segredos não poderiam ser revelados. Entretanto, o processo utilizado para constituir a rede, através de encontros sucessivos e a convivência dos empresários em cursos e palestras realizados ao longo do tempo, levou a um aumento da confiança entre todos, que passaram a compartilhar informações sobre diversos aspectos inerentes ao negócio.

Mesmo sem apoio governamental para o início do processo de formação da rede, o grupo contou com o incentivo da Câmara de Comércio e Indústria de Santa Maria (Cacism) e o apoio do Sebrae, sem os quais, na visão do empresário $\mathrm{A}$, a rede provavelmente não teria sido constituída, em função dos resultados limitados das associações formadas anteriormente na cidade. Ao promover encontros e incentivar a realização de cursos e seminários, o Sebrae influenciou decisivamente os empresários, modificando sua cultura e agregando o grupo em torno da ideia de cooperação. Nesse caso, o agente externo (representado pela Cacism e pelo Sebrae) teve papel importante para a criação da rede.

Para o empresário A, “é fundamental ficar muito claro onde $\mathrm{o}$ grupo pode chegar e que benefícios pode obter”. Também é indispensável que no início do processo haja ganhos para os participantes, especialmente financeiros, porque dessa forma o empresário deixará o ceticismo de lado e perceberá que há outros resultados possíveis. No caso da Rede Numov, o presidente acreditava que alguns ganhos já eram visíveis, em termos de qualificação da mão de obra, aquisição de tecnologia e de melhoria de processos para redução de custos. O fato de os participantes se organizarem em um grupo também viabilizou uma série de cursos e treinamentos a um custo reduzido, fazendo com que os empresários encarassem a gestão de suas empresas com mais profissionalismo.

Apesar do estágio de desenvolvimento relatado, surgiram diversas dificuldades. Como o próprio presidente da rede ressaltou à época, a falta 
de confiança entre os empresários, no início dos trabalhos, as diferenças culturais (valores, concepções) e as diferenças de perfil foram as maiores dificuldades para o andamento do grupo. Com o tempo, o trabalho conjunto e o convívio das pessoas permitiram que essas dificuldades fossem superadas, inclusive com projetos formulados na época que demonstraram a intenção de obter novos ganhos através da rede. Conforme o entrevistado, "à medida que se amplia a integração das empresas que fazem parte da rede, os associados planejam ações como a utilização de um software padronizado para a elaboração de projetos e orçamentos e a padronização das suas contabilidades".

Da mesma forma, surgiam oportunidades de vendas conjuntas que, na época, poderiam significar o incremento do faturamento das empresas. Em 2004, a rede buscou ainda firmar parceria com uma construtora, com o objetivo de mobiliar um prédio residencial que estava sendo construído na cidade, algo inviável para as empresas que atuavam individualmente. Para 2005, o projeto de expansão da rede previa o ingresso de novos associados, empresas que demonstraram interesse em integrar o grupo. Segundo o presidente, um dos requisitos mais importantes a serem observados na admissão de novos membros era o histórico do empresário e sua vivência associativa, além do fato de ele estar com as obrigações financeiras em dia.

\subsection{De Numov a Redemov: "A rede está querendo voltar a brotar"}

A Numov continuava existindo formalmente quando da segunda coleta de dados, embora eventos críticos ao longo dos últimos sete anos tenham afetado o funcionamento da rede e o interesse dos participantes. Do total de 20 associados da rede em 2004, 14 empresas continuavam formalmente associadas, mas somente sete delas participavam efetivamente das atividades da rede. As ações da rede se resumiam à participação em feiras, à exposição de móveis e a visitas técnicas. Durante um período, a rede chegou a contratar uma secretária e alugar um escritório, mas não tinha um profissional para realizar tarefas de gestão.

Em 2008, a rede modificou seu nome para Redemov e expandiu o quadro de associados para 23 empresas, com o objetivo de se enquadrar em um projeto do Ministério da Integração, do governo federal. O projeto previa a obtenção de recursos para estruturar um centro tecnológico moveleiro em Santa Maria, mas, segundo o empresário B, por questões burocráticas e atrasos da prefeitura, acabou não se concretizando e os recursos foram perdidos. A desmotivação dos empresários com a rede é atribuída, em grande medida, à frustração gerada pela não concretização 
desse projeto. Segundo o empresário A, "hoje está difícil [retomar as atividades] porque há um desgaste bem acentuado com isso aí, porque todo mundo trabalhou com essa expectativa, investiu tempo e dinheiro e na verdade não saiu nada".

Em termos de resultados gerados pela rede, o empresário A argumenta que "o grande resultado que o trabalho associativo traz é a mudança de comportamento dos empresários com as visitas técnicas. $\mathrm{O}$ trabalho em conjunto muda o perfil das empresas". O aprendizado proporcionado pela atuação em rede é destacado e colocou as empresas em outro patamar. $\mathrm{O}$ empresário $\mathrm{B}$, presidente da rede, acredita que as empresas também tiveram ganhos diretos: “a união do grupo e a mudança de concorrentes para parceiros [são ganhos importantes] e, claro, tem as questões técnicas de desenvolvimento e treinamento que nós tivemos [...]”. No entanto, embora o grupo fosse unido e sem divergências graves, o ex-presidente entrevistado ressalta que "eram poucos os empresários que realmente se dedicavam à rede, mas no final todos buscavam os louros".

Apesar de o projeto não concretizado ter gerado grande desgaste dentro do grupo, existe ainda a esperança de que novas ações possam permitir à rede voltar a ser mais atuante. A ideia de compras conjuntas é ressaltada pelo novo presidente como uma possibilidade de motivar parte do grupo e, nas suas palavras, fazer a rede "brotar novamente". No passado, quando o número de participantes era pequeno, houve um esforço para atender pedidos conjuntamente, o que não foi mais realizado com a expansão da rede e a entrada de novas empresas. Segundo o empresário A, presidente da rede em 2004, o grupo chegou a mobiliar um apartamento modelo para vender móveis em conjunto, mas o retorno não foi atrativo e a ideia foi deixada de lado. O projeto de uso de um software padronizado para a elaboração de projetos e orçamentos, planejado em 2004, acabou não se concretizando por problemas técnicos.

O papel dos agentes externos no apoio à rede é visto pelo empresário $\mathrm{B}$ sob duas perspectivas. Por um lado, estimulou o associativismo e mobilizou os empresários. Por outro lado, a rede foi apoiada por dois agentes em momentos distintos, iniciando com o Sebrae e posteriormente com o Programa Redes de Cooperação. O respondente entende que a rede já estava relativamente estruturada e esse último agente propôs um modelo diferente, agregando novos empresários ao grupo, que desestabilizaram o trabalho já existente. "Teve um afastamento do Sebrae do projeto, ele que era um articulador e um catalisador desse processo. Também teve o afastamento do projeto Redes, então hoje a gente está meio solto, estamos batalhando 
para começar a engatinhar sozinhos, então esse é o desafio". Para o empresário B, o apoio de um agente externo seria fundamental para a retomada da rede. Nas suas palavras, "é uma questão de ter por mais um tempo um parceiro, [...] um catalisador que tenha esse dom para articular o grupo e traçar durante um período de 6 meses a 1 ano um processo de amadurecimento [...] para podermos caminhar com as próprias pernas".

\subsection{Discussão}

Apesar das dificuldades enfrentadas pelas duas redes, nos dois casos os entrevistados relataram que foram alcançados importantes resultados, tanto em termos econômicos quanto de relações interpessoais. Entretanto, os achados revelam as dificuldades de obter novos e significativos resultados ao longo do tempo para manter o interesse dos empresários na rede. Isso confirma o argumento de Jarillo (1988), segundo o qual a manutenção de uma rede está condicionada à obtenção de ganhos superiores àqueles que podem ser alcançados individualmente. Os gestores da rede precisam de uma agenda de criação de valor (JÄRVENSIVU e MÖLLER, 2009) e estar atentos à necessidade de estabelecer e atingir novos objetivos que gerem resultados coletivos, superiores àqueles gerados pela própria rede no passado, e que não possam ser obtidos pelas organizações individualmente.
Somente a rede Afecom estabeleceu uma gestão profissionalizada, contratando gestores com dedicação exclusiva às atividades da rede, aspecto considerado relevante para sua consolidação, conforme Verschoore (2004), Wegner e Padula (2010) e Wegner et al. (2013). Ainda assim, a existência de uma estrutura de gestão não foi suficiente para manter a rede em funcionamento, devido à complexidade de gerenciar relações interorganizacionais, como destacado por Park e Ungson (2001), e aos eventos críticos que impactaram o grupo. No caso da rede Numov, a gestão era realizada pelos próprios empresários, dividindo-se entre as atividades da própria empresa e as da rede, com a consequente dificuldade de dedicação de tempo ao empreendimento coletivo.

Tratando-se dos relacionamentos entre as empresas, no caso específico da Afecom, as entrevistas revelaram que não houve problemas nas relações interpessoais ou quebra de confiança entre os empresários, mas ocorreram mudanças de expectativas ao longo do tempo. Conforme destacado, diversos empresários atingiram objetivos individuais e perderam parcialmente o interesse na rede, ou seja, utilizaram-se da rede para alavancar seus negócios, sem maior comprometimento com a atividade cooperativa no longo prazo. Khanna, Gulati e Nohria (1998) acreditam que é inevitável surgirem 
assimetrias de incentivos em investir na relação cooperativa à medida que a aliança ou relação interorganizacional evolui, já que algumas empresas alcançam seus objetivos individuais e outras não. Para reduzir esse problema, gestores de redes devem monitorar constantemente os interesses dos participantes e promover ajustes nos objetivos coletivos, incorporando os novos interesses dos associados.

Da mesma forma, não houve relatos de problemas relacionais na rede Numov, que superou os problemas iniciais de relacionamento derivados da heterogeneidade dos participantes. Apesar do bom ambiente relacional, um dos entrevistados destacou que poucos empresários de fato se dedicavam à rede. Portanto, a inexistência de conflitos e mesmo a confiança interpessoal desenvolvida pelos participantes podem não ser suficientes para manter a rede em funcionamento. A falta de uma estrutura de gestão com dedicação exclusiva aumenta a dependência da rede de esforços a serem realizados pelos próprios associados, fato que pode resultar em conflitos de interesses e insuficiência de tempo dos empresários para com as necessidades da rede.

Tanto no caso da rede Afecom quanto no caso da Numov, os agentes externos tiveram papel destacado como intermediários e fomentadores do processo de criação e estruturação dos grupos, como sugerido nos estudos de Casarotto e Pires (1998), Humphrey e Schmitz (1995), Verschoore (2004) e Verschoore e Balestrin (2008).

No entanto, analisando em retrospectiva, os entrevistados de ambas as redes fizeram comentários críticos sobre a atuação dos agentes externos. A Afecom ressaltou a ênfase excessiva no entusiasmo e pouco realismo dos agentes externos que a apoiaram, com foco maior em motivar os empresários para a cooperação do que em criar projetos reais de ação. No caso da Numov/Redemov, a expansão trouxe dificuldades inerentes à organização e à coordenação de um grupo maior de empresas. Com a entrada de um segundo agente externo no processo, houve uma desestruturação parcial das atividades que já vinham sendo executadas, em função da adoção de uma nova metodologia de trabalho, o que acarretou a desestabilização da rede.

Embora a literatura e o presente estudo demonstrem a importância dos agentes externos para fomentar a cooperação, a análise das entrevistas revela as limitações desses agentes em contribuir para a consolidação das redes, o que pode gerar reflexões sobre o papel e a capacidade de contribuição deles. De forma mais evidente no caso da rede Numov/Redemov, criou-se uma dependência dos agentes intermediadores, 
que, por limitações em atender as necessidades da rede, resultou em dificuldades para o desenvolvimento da cooperação.
A Figura 2 sintetiza as principais mudanças ocorridas nas duas redes no período analisado.

Figura 2 - Análise comparativa das redes Afecom e Numov em 2004 e 2011

\begin{tabular}{|c|c|c|c|c|}
\hline & $\begin{array}{l}\text { Rede Afecom } \\
\text { (2004) }\end{array}$ & $\begin{array}{l}\text { Rede Afecom } \\
\text { (2011) }\end{array}$ & $\begin{array}{l}\text { Rede Numov } \\
\text { (2004) }\end{array}$ & $\begin{array}{c}\text { Rede } \\
\text { Numov/Redemov } \\
(\mathbf{2 0 1 1}) \\
\end{array}$ \\
\hline Rede ativa? & Sim & $\begin{array}{l}\text { Não, somente } \\
\text { registrada } \\
\text { formalmente }\end{array}$ & Sim & $\begin{array}{l}\text { Sim, mas com ações } \\
\text { limitadas }\end{array}$ \\
\hline $\begin{array}{l}\text { Número de } \\
\text { Associados }\end{array}$ & 21 & 0 & 20 & 23 \\
\hline $\begin{array}{c}\text { Gestão da } \\
\text { cooperação }\end{array}$ & $\begin{array}{l}\text { Contratação de } \\
\text { profissional para } \\
\text { executar as } \\
\text { atividades de } \\
\text { gestão da rede. }\end{array}$ & $\begin{array}{l}\text { Inexistência na rede } \\
\text { de gestores } \\
\text { instituídos } \\
\text { (empresários) ou } \\
\text { contratados } \\
\text { (profissionais). } \\
\end{array}$ & $\begin{array}{l}\text { Gestão realizada } \\
\text { pelos empresários, } \\
\text { com uma secretária } \\
\text { contratada. }\end{array}$ & $\begin{array}{c}\text { Gestão } \\
\text { desestruturada. } \\
\text { Somente os cargos de } \\
\text { presidente e vice- } \\
\text { presidentes são } \\
\text { ocupados. }\end{array}$ \\
\hline $\begin{array}{l}\text { Ambiente } \\
\text { relacional da } \\
\text { rede }\end{array}$ & $\begin{array}{l}\text { Heterogeneidade } \\
\text { excessiva do } \\
\text { ambiente da rede, } \\
\text { gerando } \\
\text { dificuldades de } \\
\text { relacionamento. } \\
\text { Falta de cultura } \\
\text { associativa. }\end{array}$ & $\begin{array}{c}\text { Continuidade de } \\
\text { troca de informações } \\
\text { entre alguns } \\
\text { empresários, mesmo } \\
\text { com o encerramento } \\
\text { da rede. }\end{array}$ & $\begin{array}{l}\text { Dificuldades iniciais, } \\
\text { como a falta de } \\
\text { confiança, foram } \\
\text { superadas com o } \\
\text { passar do tempo. }\end{array}$ & $\begin{array}{c}\text { Desenvolvimento de } \\
\text { parceria e união no } \\
\text { grupo, mas poucos } \\
\text { empresários } \\
\text { envidavam esforços } \\
\text { para o sucesso da } \\
\text { rede. }\end{array}$ \\
\hline $\begin{array}{l}\text { Apoio de } \\
\text { Agentes } \\
\text { externos }\end{array}$ & $\begin{array}{l}\text { Apoio de diversas } \\
\text { entidades para a } \\
\text { criação e a } \\
\text { organização da } \\
\text { rede. }\end{array}$ & $\begin{array}{l}\text { Auxílio dos agentes } \\
\text { externos de curto } \\
\text { prazo, muito } \\
\text { entusiástico, com } \\
\text { foco motivacional e } \\
\text { pouco realista. }\end{array}$ & $\begin{array}{c}\text { Importância do papel } \\
\text { do Sebrae para a } \\
\text { constituição e a } \\
\text { organização da rede. }\end{array}$ & $\begin{array}{c}\text { Entrada de um novo } \\
\text { agente externo gerou } \\
\text { desgaste. Novo apoio } \\
\text { de um agente externo } \\
\text { poderia motivar os } \\
\text { remanescentes. }\end{array}$ \\
\hline $\begin{array}{l}\text { Eventos } \\
\text { críticos }\end{array}$ & \multicolumn{2}{|c|}{$\begin{array}{l}\text { (1) Resultados esperados não atingidos em } \\
\text { ações de venda conjunta com a marca da } \\
\text { rede. } \\
\text { (2) Desligamento de empresas incapazes de } \\
\text { realizar os investimentos exigidos pela } \\
\text { rede. } \\
\text { (3) Desligamento de muitas empresas } \\
\text { devido à queda da cotação do dólar, já que } \\
\text { um dos objetivos da rede era a exportação. }\end{array}$} & \multicolumn{2}{|c|}{$\begin{array}{l}\text { (1) Impacto negativo no desenvolvimento da } \\
\text { rede provocado pela expansão para nível } \\
\text { regional, e pela entrada de novas empresas } \\
\text { para se enquadrarem em projeto de captação } \\
\text { de recursos. } \\
\text { (2) Frustração com um projeto desenvolvido } \\
\text { pela rede em parceria com os governos } \\
\text { municipal e federal como fator de } \\
\text { desmotivação dos empresários e de } \\
\text { desestabilização da rede. }\end{array}$} \\
\hline $\begin{array}{l}\text { Resultados } \\
\text { alcançados }\end{array}$ & $\begin{array}{l}\text { Criação de um CD } \\
\text { nos Estados } \\
\text { Unidos, compra e } \\
\text { venda através da } \\
\text { rede, melhoria na } \\
\text { qualidade } \\
\text { relacionamentos. }\end{array}$ & $\begin{array}{l}\text { Manutenção do } \\
\text { relacionamento entre } \\
\text { algumas empresas, } \\
\text { mesmo com o } \\
\text { encerramento da } \\
\text { rede. }\end{array}$ & $\begin{array}{l}\text { Desenvolvimento de } \\
\text { uma cultura de } \\
\text { cooperação e } \\
\text { realização de vendas } \\
\text { conjuntas. }\end{array}$ & $\begin{array}{c}\text { Aprendizado e } \\
\text { mudanças culturais, } \\
\text { bem como ganhos em } \\
\text { termos de } \\
\text { faturamento. }\end{array}$ \\
\hline
\end{tabular}

Fonte: Elaborado pelos autores.

Assim como no caso de organizações individuais, redes cooperativas estão sujeitas a eventos críticos que afetam o interesse dos participantes e a própria continuidade da rede. A diferença em relação às 
organizações individuais é que as redes de caráter colaborativo dependem da participação voluntária dos empresários. A dificuldade em alcançar um objetivo ou a ocorrência de um evento crítico (como o projeto frustrado da Numov/Redemov) podem desmotivar os empresários e esvaziar a rede, levando inclusive à sua dissolução. A retomada das atividades passa, então, a depender de empresários remanescentes ou visionários, que encontrem novos objetivos coletivos e tenham motivação para colocá-los em prática, para depois atrair novos interessados.

A análise dos casos também permitiu compreender as dificuldades oriundas da cooperação entre empresas com diferenças estruturais e culturais. Quando a heterogeneidade dos membros da rede é elevada, o desenvolvimento e a manutenção desses membros ficam comprometidos, principalmente em casos em que a visão e o comprometimento associativo não são compartilhados igualmente pelos empresários. Uma melhor avaliação para a seleção dos membros da rede também se faz necessária, para que se evite a inclusão de empresas com objetivos imediatistas e sem perfil para investir nas atividades colaborativas.

Os casos analisados confirmam o estudo de Sydow (2003) sobre a dinâmica das organizações em rede e a nãolinearidade no desenvolvimento de RIOs.
Segundo o autor, isso faz com que a continuidade de longo prazo de uma rede dependa em grande medida da capacidade do grupo de reiniciar as atividades após eventos críticos, mesmo que seja necessário retornar a estágios anteriores de desenvolvimento. Esse parece ser o caso da rede Numov/Redemov, que considera a possibilidade de retomar as atividades cooperativas e busca novos objetivos para motivar os empresários remanescentes.

Atendendo à sugestão de Sydow (2003) e Cropper e Palmer (2008) quanto às lacunas teóricas sobre a dinâmica e a transitoriedade das RIOs, o artigo demonstra as modificações a que estão sujeitas as redes ao longo do tempo, como consequência das ações dos seus participantes e dos eventos críticos não controláveis que afetam sua trajetória. Outra importante questão recai sobre o monitoramento das expectativas dos empresários ao longo do tempo, visando a busca de novos objetivos comuns para evitar a dissolução da rede. Ademais, a adoção de uma estrutura própria de gestão pode amenizar problemas referentes à falta de envolvimento dos empresários com as atividades cooperativas, como também atenuar o efeito de eventos críticos.

\section{CONSIDERAÇÕES FINAIS}

Apesar do grande número de estudos que analisam a estrutura, a gestão e os resultados gerados por RIOs, poucos 
abordam as mudanças que ocorrem em tais relações ao longo do tempo. Assim, o presente estudo teve como objetivo analisar a dinâmica de duas redes interorganizacionais formadas por pequenas e médias indústrias de móveis no Rio Grande do Sul, comparando a sua situação nos anos de 2004 e 2011.

Uma das contribuições teóricas do estudo foi a ênfase na análise da dinâmica de duas redes de empresas, ao contrário do caráter estático da maioria dos estudos sobre o tema, como sugerido por Oelsnitz e Tiberius (2007) e Tiberius (2008). Essa perspectiva permitiu confirmar os argumentos de Khanna, Gulati e Nohria (1998) quanto às mudanças de expectativas dos empresários ao longo do tempo e a importância de monitorá-las, visando identificar novos objetivos para a cooperação e evitar a dissolução da rede. No caso da Afecom, isso parece ter sido decisivo para o encerramento da rede.

Além de considerar a dinâmica das redes, outra contribuição do artigo é a compreensão do impacto de eventos críticos para a continuidade das redes de empresas, uma vez que elas dependem da participação voluntária e dos interesses dos empresários. Quando esses empresários se desmobilizam, a rede torna-se incapaz de agir, e a manutenção da cooperação corre sérios riscos. Em ambos os casos analisados, os eventos críticos influenciaram significativamente a trajetória das redes, a ponto de uma delas ter encerrado completamente as atividades e a outra encontrar-se praticamente inativa. Ainda que a rede se esforce para gerenciar as mudanças e buscar seu desenvolvimento de maneira planejada, ocorrem eventos críticos inesperados que afetam sua trajetória e podem levar ao encerramento da cooperação.

Verificou-se ainda que a participação voluntária dos empresários para o gerenciamento da rede, vista como um entrave ao seu desenvolvimento, poderia ser superada com a criação de uma estrutura própria de gestão da rede, reduzindo o envolvimento dos empresários com atividades operacionais do arranjo colaborativo. Enquanto a rede depende exclusivamente da doação de tempo dos empresários para sua gestão, ela corre o risco permanente de ter seu funcionamento ameaçado, pela simples restrição de tempo dos empresários para gerenciar seu próprio negócio e a rede. Uma estrutura de gestão com funcionários ou gestores contratados pode liberar os empresários das atividades operacionais, concentrando-se nas decisões estratégicas e na reflexão sobre o futuro da rede.

Ainda que a pesquisa se caracterize por dois estudos de caso, o fato de que ambas as redes tenham passado por dificuldades e uma delas tenha encerrado as atividades em definitivo indica que pode ser mais simples constituir RIOs do que 
gerenciá-las e fazer com que perdurem ao longo do tempo. Apesar da relevância dos entrevistados na trajetória das redes investigadas, tratando-se de presidentes e vice-presidentes, o baixo número de respondentes é uma das limitações deste estudo. Outra limitação refere-se à análise exclusivamente qualitativa dos benefícios e resultados gerados pelas redes, de acordo com a percepção dos entrevistados. Sugere-se que pesquisas futuras analisem um número maior de redes, identificando os eventos críticos de sua trajetória e trazendo informações sobre o percentual de redes que efetivamente sobrevivem com o passar do tempo. A aplicação de métodos que compreendam uma análise mais objetiva e abrangente sobre a dinâmica das redes e que possam gerar dados quantitativos a respeito do impacto de eventos críticos para sua manutenção e desenvolvimento também é recomendada.

\section{REFERÊNCIAS}

AHLSTRÖM-SÖDERLING, R. SME strategic business networks seen as learning organizations. Journal of Small Business and Enterprise Development, v. 10, n. 4, p. 444-454, 2003.

AHUJA, G.; SODA; G.; ZAHEER, A. The Genesis and Dynamics of Organizational networks. Organization Science, v. 23, n. 2, p. 434-448, 2012.

ALBERS, S. Configurations of alliance governance systems. Schmalenbach

Business Review, v. 62, p. 204-233, 2010.
AMALDOSS, W, MEYER, R. J, RAJU, J. S.; RAPOPORT, A. Collaborating to Compete. Marketing Science, v. 19, n. 2, 105-126, 2000.

ANDRADE, C. H. M.; REZENDE, S. F. L.; SALVATO, M. A.; BERNARDES, P. A relação entre confiança e custos de transação em relacionamentos interorganizacionais. Revista de Administração Contemporânea, v. 15, n. 4, p. 608-630, 2011.

AXELROD, R. The Evolution of Cooperation. New York: Harper Collins, 1984.

BACHMANN, R. Trust, power and control in trans-organizational relations.

Organization Studies, v. 22, n. 2, p. 337 $365,2001$.

BALESTRIN, A.; VARGAS, L. M. A Dimensão Estratégica das Redes Horizontais de PMEs: Teorizações e Evidências. Revista de Administração Contemporânea (RAC), v. 8 (núm. especial), p. 203-227, 2004.

BALESTRO, M.; MESQUITA, Z. Redes de pequenas empresas em Sistemas Locais de Produção: a experiência da Rede de Estofadores do Polo Moveleiro do RS. In: IV Colóquio sobre Transformaciones Territoriales Sociedad, Território y Sustentabilidad: Perspectivas desde el Desarrollo Regional y Local. Anais... Montevidéu, Uruguai. 2002.

CASAROTTO, N.; PIRES, L. H. Redes de pequenas e médias empresas e desenvolvimento local. São Paulo: Atlas. 1998.

CASTRO, M.; BULCAGOV, S.; HOFFMANN, V. E. Relacionamentos Interorganizacionais e Resultados: estudo em uma rede de cooperação horizontal da região central do Paraná. Revista de 
Administração Contemporânea (RAC), v. 15, n. 1. art. 2, p. 25-46, 2011.

CHILD, J. Learning through strategic alliances. In Dierkes, M. Organizational learning and knowledge (p. 657-680). Oxford: Oxford University Press, 2001.

CROPPER, S.; PALMER, I. Change, Dynamics, and Temporality in InterOrganizational Relationships. In: CROPPER, S., EBERS, M., HUXHAM, C., SMITH RING, P. (2008). The Oxford Handbook of Inter-organizational relations (p. 635-663). Oxford: Oxford University Press, 2008.

CUNHA, J. A. C.; PASSADOR, J. L.; PASSADOR, C. S. A presença de agentes intermediadores na formação de redes interorganizacionais: uma análise sob a perspectiva temporal. Cadernos Ebape. br, v. 10, n. 1, p. 109-128, 2012.

DENZIN, N. K.; LINCOLN, Y. S. O planejamento da pesquisa qualitativa. Porto Alegre: Artmed, 2006.

DOZ, Y. The evolution of cooperation in strategic alliances: Initial conditions or learning processes? Strategic

Management Journal, v. 17, n. 1, p. 5583, 1996.

EBERS, M.; GRANDORI, A. The Forms, Costs, and Development Dynamics of Inter-Organizational Networking. In: EBERS, $M$. The formation of interorganizational networks (p. 265-286). New York: Oxford University Press, 1999.

ESTEVES, G.; NOHARA, J. J. Fatores críticos à estabilidade das alianças estratégicas das micro e pequenas empresas. Revista de Administração e Inovação, v. 8, n. 3, p. 182-204, 2011.
FLICK, U. Desenho da pesquisa qualitativa. Porto Alegre: Artmed, 2009.

FLORÉN, H.; TELL, J. The emergent prerequisites of managerial learning in small firms networks. Leadership and Organization Development Journal, v. 25, p. 292-307, 2004.

FRANCO, M. J. B. Tipologia de Processos de Cooperação Empresarial: uma investigação empírica sobre o caso portugues. Revista de Administração Contemporânea (RAC), v. 11, n. 3, p. 149-176, 2007.

GRANDORI, A.; SODA, G. Inter-firm networks: Antecedents, mechanisms and forms. Organization Studies, v. 16, n. 2, p. 183-214, 1995.

HASTENREITER FILHO, H. N. As organizações de suporte e as redes interorganizacionais no Brasil: diagnóstico e propostas para os programas brasileiros de cooperação entre empresas. In: VERSCHOORE, J. R. S. (Org.) Redes de cooperação: uma nova organização de pequenas e médias empresas no Rio Grande do Sul. Porto Alegre: FEE, p. 109128, 2004.

HIBBERT, P. HUXHAM, C.; SMIITH RING, P. Managing collaborative interorganizational relations. In CROPPER, S., EBERS, M., HUXHAM, C., SMITH RING, P. The Oxford Handbook of Inter-organizational relations (p. 391416). Oxford: Oxford University Press, 2008.

HUANG, Y.; WILKINSON, I. F. The dynamics and evolution of trust in business relationships. Industrial Marketing Management, v. 42, n. 3, p. 455-465, 2013.

HUMPHREY, J.; SCHMITZ, H. Principles for promoting clusters \& 
networks of SMEs, United Nations Industrial Development Organization.

Discussion Paper No. 1. Vienna.

Disponível em

$<$ http://www.unido.org/fileadmin/media/do cuments/pdf/SME_Cluster/

Humphrey.pdf $>$ Acesso em: 08 out. 2012.

JARILLO, J. C. On strategic networks.

Strategic Management Journal, v. 9, n. 1, p. 31-41, 1988 .

JÄRVENSIVU, T.; MÖLLER, K. Metatheory of network management: A contingency perspective. Industrial Marketing Management, v. 38, p. 654$661,2009$.

JIANG, X.; LI, Y.; GAO, S. The stability of strategic alliances: Characteristics, factors and stages. Journal of International Management, v. 14, n. 2, p. 173-189, 2008.

KHANNA, T; GULATI, R.; NOHRIA, N. The dynamics of learning alliances: competition, cooperation, and relative scope. Strategic Management Journal, v. 19, p. 193-210, 1998.

KRISHNAN, R.; MARTIN, X.; NOORDERHAVEN, N. G. When does trust matter to alliance performance? Academy of Management Journal, v. 49, n. 5, p. 894-917, 2006.

MELLAT-PARAST, M., DIGMAN A. Learning: the interface of quality management and strategic alliances. International Journal of Production Economics, v. 114, n. 2, p. 820-829, 2008.

OELSNITZ, D.; TIBERIUS, V. A. Zur Dynamisierung interorganisationaler Lernstrategien: Pfade zwischen Kooperation und Wettbewerb. In Schreyögg, G., \& Sydow, J. (Eds), Kooperation und Konkurrenz (p. 121-
159). Wiesbaden, Deutschland: Gabler Edition, 2007.

OLIVEIRA, A. L., REZENDE, D. C., CARVALHO, C. C. Redes

Interorganizacionais Horizontais Vistas como Sistemas Adaptativos Complexos Coevolutivos: o Caso de uma Rede de Supermercados. Revista de Administração Contemporânea (RAC), v. 15, n1, art 4, p. 67-83, 2011.

PARK, S.H.; UNGSON, G. Interfirm rivalry and managerial complexity: a conceptual framework of alliance failure. Organization Science, v. 12, n. 1, p. 3753, 2001.

PROVAN, K. G.; LEMAIRE, R. H. Core concepts and key ideas for understanding public sector organizational networks: Using research to inform scholarship and practice. Public Administration Review, v. 72, n. 5, p. 638-648, 2012.

RING, P. S.; VAN DE VEN, A. H. Developmental processes of cooperative interorganizational relationship. Academy of Management Review, v. 19, n. 1, p. 90 $118,1994$.

SCHILKE, O.; COOK, K. S. A cross-level process theory of trust development in interorganizational relationships. Strategic Organization, v. 11, n. 3, p. 281-303, 2013.

SESAMPE - SECRETARIA DA ECONOMIA SOLIDÁRIA E APOIO À MICRO E PEQUENA EMPRESA. Rede de Cooperação gaúcha é destaque em convenção nacional. 2013. Disponível em: $<$ http://www.sesampe.rs.gov.br/?model $=\mathrm{co}$ $\underline{n t e u d o \& m e n u}=2 \& \mathrm{id}=4416>$. Acesso em: 15 mar. 2014.

SPEKMAN, R. E.; FORBES, T. M.; ISABELLA, L. A.; MACAVOY, T. C. Alliance management: a view from the 
past and a look to the future. Journal of Management Studies, v. 35, n. 6, p. 747772, 1998.

SYDOW, J. Network development by means of network evaluation? Explorative insights from a case in the financial services industry. Human Relations, v. 57, n. 2, p. 201-220, 2004.

SYDOW, J. Dynamik von

Netzwerkorganisationen - Entwicklung, Evolution, Strukturation. In Hoffmann, W.

\section{$\mathrm{H}$. Die Gestaltung der}

Organisationsdynamik: Konfiguration und Evolution (p. 327-356). Stuttgart:

Schäffer-Poeschel Verlag Stuttgart, 2003.

SYDOW, J. Management von

Netzwerkorganisationen - Zum Stand der Forschung. In: Sydow, J. (Org.)

Management von

Netzwerkorganisationen. Wiesbaden: Gabler, p. 387-472, 2006.

SYDOW, J. Understanding the constitution of interorganizational trust. In Lane, C., \& Bachmann, R. (Eds.) Trust within and between organizations: Conceptual issues and empirical applications (p. 31-63).

Oxford: Oxford University Press, 1998.

TIBERIUS, V. Prozesse und Dynamik des Netzwerkwandels. Wiesbaden, Deutschland: Gabler Edition Wissenschaft, 2008.

VERSCHOORE, J. R. S. Redes de cooperação: concepções teóricas e verificações empíricas. In VERSCHOORE, J. R. S. (Org.). Redes de cooperação: uma nova organização de pequenas e médias empresas no Rio Grande do Sul. Porto Alegre: FEE, p. 1546, 2004.
VERSCHOORE, J. R. S.; BALESTRIN, A. Fatores Relevantes para o Estabelecimento de Redes de Cooperação entre Empresa do Rio Grande do Sul.

Revista de Administração Contemporânea (RAC), v. 12, n.4, p. 1043-1069, 2008.

VLAAR, P. W. L.; VAN DEN BOSCH, F. A. J.; VOLBERDA, H. W. On the evolution of trust, distrust, and formal coordination and control in interorganizational relationships: Toward an integrative framework. Group Organization Management, v. 32, n. 4, p. 407-428, 2007.

WEGNER, D.; ZEN, A. C.; ANDINO, B. F. A. O último que sair apaga as luzes: motivos para a desistência da cooperação e encerramento de redes de empresas.

Revista de Negócios (Online), v. 16, p. 3050, 2011 .

WEGNER, D.; ALIEVI, R. M.; BEGNIS, H. S. M.; MAEHLER, A. E. The Dynamics of Cooperation: Proposal of a Small-Firms Networks Life Cycle Model. In: Proceedings of the 15th International Academy of Management and Business Conference, Lisboa, 2013.

WEGNER, D.; PADULA, A. D.

Governance and Management of Horizontal Business Networks: An Analysis of Retail Networks in Germany. International Journal of Business and Management, v. 5, n. 12, p. 74-88, 2010.

ZINELDIN, M. Developing and managing a romantic business relationship: life cycle and strategies. Managerial Auditing Journal, v. 17, n. 9, p. 546-558, 2002. 